\title{
Spektrum Signless-Laplace dan Spektrum Detour Graf Konjugasi dari Grup Dihedral
}

\author{
Abdussakir ${ }^{1, a)}$ dan Rhoul Khasanah ${ }^{1, b)}$ \\ ${ }^{1}$ Jurusan Matematika, Fakultas Sains dan Teknologi, UIN Maulana Malik Ibrahim Malang \\ a)email:sakir@mat.uin-malang.ac.id \\ b)email: rhoulkhasanah@gmail.com
}

\begin{abstract}
Abstrak
Misalkan $G$ graf berhingga yang tidak memuat loop dan sisi rangkap. Matriks keterhubungan titik $A(G)$ dari graf $G$ adalah matriks dengan entri $a_{i j}=1$ jika $v_{i}$ terhubung langsung dengan $v_{j}$ dan $a_{i j}=0$ untuk lainnya. Matriks derajat $D(G)$ dari graf $G$ adalah matriks diagonal dengan entri $d_{i i}$ merupakan derajat titik $v_{i}$ di $G$. Matriks signless-Laplace dari graf $G$ adalah $L^{+}(G)=D(G)+A(G)$. Matriks detour $D D(G)$ dari graf $G$ adalah matriks dengan entri $d d_{i j}$ merupakan panjang lintasan terpanjang dari $v_{i}$ ke $v_{j}$. Spektrum dari suatu matriks merupakan matriks yang memuat nilai eigen pada baris pertama dan multiplisitas masing-masing nilai eigen pada baris kedua. Spektrum yang diperoleh dari matriks $L^{+}(G)$ disebut spektrum signless-Laplace sedangkan spektrum yang diperoleh dari matriks $D D(G)$ disebut spektrum detour. Penelitian ini menyajikan rumus untuk menghitung spektrum signless-Laplace graf konjugasi dari grup dihedral $D_{2 n}$ untuk $n$ ganjil $(n \geq 5)$ dan spektrum detour graf konjugasi dari grup dihedral $D_{2 n}$ untuk $n$ ganjil $(n \geq 3)$ dan $n$ genap $(n \geq 6)$.

Kata kunci: spektrum, graf konjugasi, matriks signless-Laplace, matriks detour, grup dihedral
\end{abstract}

\section{Abstract}

Let $G$ be a finite graph without loops and multiple edges. The adjacency matrix $A(G)$ of graph $G$ is a matrix where $a_{i j}=1$ if $v_{i}$ is adjacent with $v_{j}$ and $a_{i j}=0$ for the others. The degree matrix $D(G)$ of graph $G$ is a diagonal matrix where $d_{i i}$ is degree of $v_{i}$ in $G$. The signless-Laplacian matrix of graph $G$ is defined by $L^{+}(G)$ $=D(G)+A(G)$. The detour matrix $D D(G)$ of graph $G$ is a matrix where $d d_{i j}$ is the length of longest path between $v_{i}$ and $v_{j}$. The spectrum of matrix is a matrix that contains its eigenvalues in the first row and the algebraic multiplicity of each eigenvalue in the second row. The spectrum of matrix $L^{+}(G)$ is called signlessLaplacian spectrum of $G$ and the spectrum of matrix $D D(G)$ is called detour spectrum of $G$. This study presents a formula for calculating the signless-Laplacian spectrum of conjugate graph of dihedral group $D_{2 n}$ for odd $n(n \geq 5)$ and detour spectrum of conjugate graph of dihedral groups $D_{2 n}$ for odd $n(n \geq 3)$ and even $n(n \geq 6)$.

Keywords: spectrum, conjugate graph, signless-Laplacian matrix, detour matrix, dihedral group

\section{Pendahuluan}

Graf $G=(V, E)$ memuat himpunan berhingga $V$ dan himpunan $E$. Himpunan $V$ tidak boleh kosong dan anggotanya disebut titik dari $G$. Himpunan $E$ boleh kosong dan anggotanya adalah pasangan tak berurutan dari unsur-unsur berbeda di $V$. Anggota himpunan $E$ disebut sisi dari $G$. Kardinalitas $V$ disebut order dari $G$ sedangkan kardinalitas $E$ disebut ukuran dari $G$ [1]. Jika $e=(a, b) \in E$ maka titik $a$ dan $b$ disebut terhubung langsung [2]. Jika $a \in V$ maka banyaknya titik di $G$ yang terhubung langsung dengan $a$ disebut derajat dari $a$ dan ditulis $\operatorname{deg}(a)$ [3]. 
Misalkan $V=\left\{v_{1}, v_{2}, \ldots, v_{p}\right\}$ adalah himpunan titik di graf $G$. Matriks keterhubungan $A(G)$ dari graf $G$ adalah matriks berordo $p \times p$ dengan $a_{i j}=1$ jika $\left(v_{i}, v_{j}\right) \in E$ dan $a_{i j}=0$ untuk lainnya [2]. Matriks derajat $D(G)$ dari graf $G$ adalah matriks diagonal berordo $p \times p$ dengan $d_{i i}=\operatorname{deg}\left(v_{i}\right)$. Matriks $L^{+}(G)=D(G)+A(G)$ disebut matriks signless-Laplace dari graf $G[4]$.

Lintasan- $v_{1} v_{n}$ pada graf $G$ adalah barisan titik-titik berbeda $v_{1}, v_{2}, \ldots, v_{n}$ sedemikian hingga $\left(v_{i}, v_{i+1}\right) \in$ E, untuk $i=1,2, . ., n-1$. Graf $G$ disebut graf terhubung jika untuk setiap dua titik berbeda $u$ dan $v$ di $G$ selalu terdapat lintasan-uv di $G$ [3]. Misalkan $G$ adalah graf terhubung dengan order $p$. Matriks detour $D D(G)$ dari $G$ adalah matriks berordo $p \times p$ sedemikian hingga $d d_{i j}$ adalah panjang lintasan terpanjang dari $v_{i}$ ke $v_{j}$ di $G[5]$.

Misalkan $\lambda_{1}, \lambda_{2}, \ldots, \lambda_{n}$ dengan $\lambda_{1}>\lambda_{2}>\ldots>\lambda_{n}$ adalah nilai eigen berbeda suatu matriks dari graf $G$ dan misalkan $m\left(\lambda_{1}\right), m\left(\lambda_{2}\right), \ldots, m\left(\lambda_{n}\right)$ adalah multiplisitas aljabar dari masing-masing $\lambda_{i}$. Matriks berordo $2 \times n$ yang memuat $\lambda_{1}, \lambda_{2}, \ldots, \lambda_{n}$ pada baris pertama dan $m\left(\lambda_{1}\right), m\left(\lambda_{2}\right), \ldots, m\left(\lambda_{n}\right)$ pada baris kedua disebut spektrum graf $G$ dan ditulis $\operatorname{Spec}(G)[6]$. Spektrum yang diperoleh dari matriks $L^{+}(G)$ disebut spektrum signless Laplace [7] dan dinotasikan dengan $\operatorname{spec}_{L_{+}}(G)$ dan spektrum dari matriks $D D(G)$ disebut spektrum detour [5] dan dinotasikan dengan $\operatorname{spec}_{D D}(G)$.

Perkembangan terbaru dalam teori graf membahas graf yang diperoleh dari grup, misalnya graf konjugasi. Misalkan $G$ grup tak komutatif. Unsur $g$ dan $h$ di $G$ dikatakan saling konjugasi jika ada $x$ di $G$ sehingga $g=x h x^{-1}$. Graf konjugasi dari grup $G$ adalah graf yang memuat semua anggota grup $G$ sebagai titik dan dua titik berbeda akan terhubung langsung jika keduanya saling konjugasi [8]. Dengan kata lain, misalkan semua kelas konjugasi di $G$ adalah $[e],\left[g_{1}\right],\left[g_{2}\right], \ldots,\left[g_{n}\right]$. Pada graf konjugasi dari grup $G$, unsur $h$ akan terhubung langsung ke $g_{i}$ jika $h \in\left[g_{i}\right][9]$.

Beberapa penelitian mengenai spektrum signless-Laplace dan spektrum detour sudah dilakukan, misalnya $[5,7,10-12]$. Di lain pihak penelitian terkait graf konjugasi juga telah dilakukan, misalnya $[8,9]$. Meskipun demikian, belum ada yang mengkaji spektrum signless-Laplace dan spektrum detour graf konjugasi dari grup dihedral. Oleh sebab itu, maka pada penelitian ini dikaji spektrum signless-Laplace dan spektrum detour graf konjugasi dari grup dihedral.

\section{Metode}

Penelitian ini merupakan penelitian kepustakaan. Penentuan rumus spektrum signless-Laplace dan

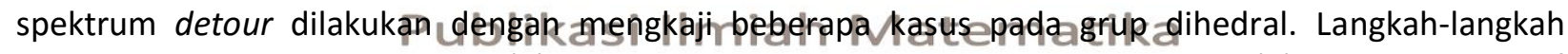
pencairan pola dilakukan dengan (1) menentukan klas konjugasi pada grup dihedral, (2) menggambar graf konjugasi, (3) menentukan matriks keterhubungan dan matriks derajat untuk memperoleh matriks signless-Laplace serta menentukan matriks detour, (4) menentukan polinomial karakteristik matriks signless-Laplace dan matriks detour serta menganalisis polanya, (5) menentukan spektrum signlessLaplace dan spektrum detour, (6) menganalisis pola dari beberapa spektrum signless-Laplace dan spektrum detour, dan (7) menyatakan pola yang diperoleh sebagai teorema dan dilengkapi dengan buktinya.

\section{Hasil dan Diskusi}

Berdasarkan pengamatan pada pola spektrum signless-Laplace graf konjugasi dari grup dihedral, maka diperoleh hasil sebagai berikut.

\section{Teorema 1}

Polinomial karakteristik matriks signless-Laplace graf konjugasi dari grup dihedral $D_{2 n}$ untuk bilangan asli ganjil $n$ dan $n \geq 5$ adalah

\section{Bukti}

$$
p(\lambda)=\lambda^{\frac{n+1}{2}}(\lambda-2)^{\frac{n-1}{2}}(\lambda-(n-2))^{n-1}(\lambda-(2 n-2)) .
$$

Diketahui grup dihedral $D_{2 n}=\left\{1, r, r^{2}, \ldots, r^{n-1}, s, s r, s r^{2}, \ldots, s r^{n-1}\right\}$. Untuk $n$ ganjil diperoleh kelas konjugasi $[1]=\{1\},[r]=\left\{r, r^{n-1}\right\},\left[r^{2}\right]=\left\{r^{2}, r^{n-2}\right\}, \ldots,\left[r^{\frac{n-1}{2}}\right]=\left\{r^{\frac{n-1}{2}}, r^{\frac{n-1}{2}+1}\right\}$, dan $[s]=$ 
$\left\{s, s r, s r^{2}, \ldots s r^{n-1}\right\}$. Sesuai definisi graf konjugasi, maka unsur dalam satu kelas konjugasi akan saling terhubung langsung dan unsur dalam kelas konjugasi berbeda tidak akan saling terhubung langsung. Dengan demikian diperoleh matriks keterhubungan titik

$\left.\begin{array}{ccccccccccccc} & 1 & r & r^{2} & \cdots & r^{n-1} & s & s r & s r^{2} & \cdots & s r^{n-2} & s r^{n-1} \\ 1 & 0 & 0 & 0 & \cdots & 0 & 0 & 0 & 0 & \cdots & 0 & 0 \\ r & 0 & 0 & 0 & \cdots & 1 & 0 & 0 & 0 & \cdots & 0 & 0 \\ r^{2} & 0 & 0 & 0 & \cdots & 0 & 0 & 0 & 0 & \cdots & 0 & 0 \\ \vdots & \vdots & \vdots & \vdots & & \vdots & \vdots & \vdots & \vdots & & \vdots & \vdots \\ r^{n-1} & 0 & 1 & 0 & \cdots & 0 & 0 & 0 & 0 & \cdots & 0 & 0 \\ s & 0 & 0 & 0 & \cdots & 0 & 0 & 1 & 1 & \cdots & 1 & 1 \\ s r & 0 & 0 & 0 & \cdots & 0 & 1 & 0 & 1 & \cdots & 1 & 1 \\ s r^{2} & 0 & 0 & 0 & \cdots & 0 & 1 & 1 & 0 & \cdots & 1 & 1 \\ \vdots & \vdots & \vdots & \vdots & & \vdots & \vdots & \vdots & \vdots & & \vdots & \vdots \\ s r^{n-2} & 0 & 0 & 0 & \cdots & 0 & 1 & 1 & 1 & \cdots & 0 & 1 \\ s r^{n-1} & 0 & 0 & 0 & \cdots & 0 & 1 & 1 & 1 & \cdots & 1 & 0\end{array}\right)$

dan matriks derajat

$$
\left.\begin{array}{c|ccccccccccc}
\multicolumn{1}{l}{} & 1 & r & r^{2} & \cdots & r^{n-1} & s & s r & s r^{2} & \cdots & s r^{n-2} & s r^{n-1} \\
1 & 0 & 0 & 0 & \cdots & 0 & 0 & 0 & 0 & \cdots & 0 & 0 \\
r & 0 & 1 & 0 & \cdots & 0 & 0 & 0 & 0 & \cdots & 0 & 0 \\
r^{2} & 0 & 0 & 1 & \cdots & 0 & 0 & 0 & 0 & \cdots & 0 & 0 \\
\vdots & \vdots & \vdots & \vdots & & \vdots & \vdots & \vdots & \vdots & & \vdots & \vdots \\
r^{n-1} & 0 & 0 & 0 & \cdots & 1 & 0 & 0 & 0 & \cdots & 0 & 0 \\
s & 0 & 0 & 0 & \cdots & 0 & n-1 & 0 & 0 & \cdots & 0 & 0 \\
s r & 0 & 0 & 0 & \cdots & 0 & 0 & n-1 & 0 & \cdots & 0 & 0 \\
s r^{2} & 0 & 0 & 0 & \cdots & 0 & 0 & 0 & n-1 & \cdots & 0 & 0 \\
\vdots & \vdots & \vdots & \vdots & & \vdots & \vdots & \vdots & \vdots & & \vdots & \vdots \\
s r^{n-2} & \vdots & 0 & 0 & \cdots & 0 & 0 & 0 & 0 & \cdots & n-1 & 0 \\
s r^{n-1} & 0 & 0 & 0 & \cdots & 0 & 0 & 0 & 0 & \cdots & 0 & n-1
\end{array}\right)
$$

Maka matriks signless-Laplace $L^{+}\left(\Gamma\left(D_{2 n}\right)\right)$ graf konjugasi dari grup dihedral $D_{2 n}$ untuk $\mathrm{n}$ ganjil adalah

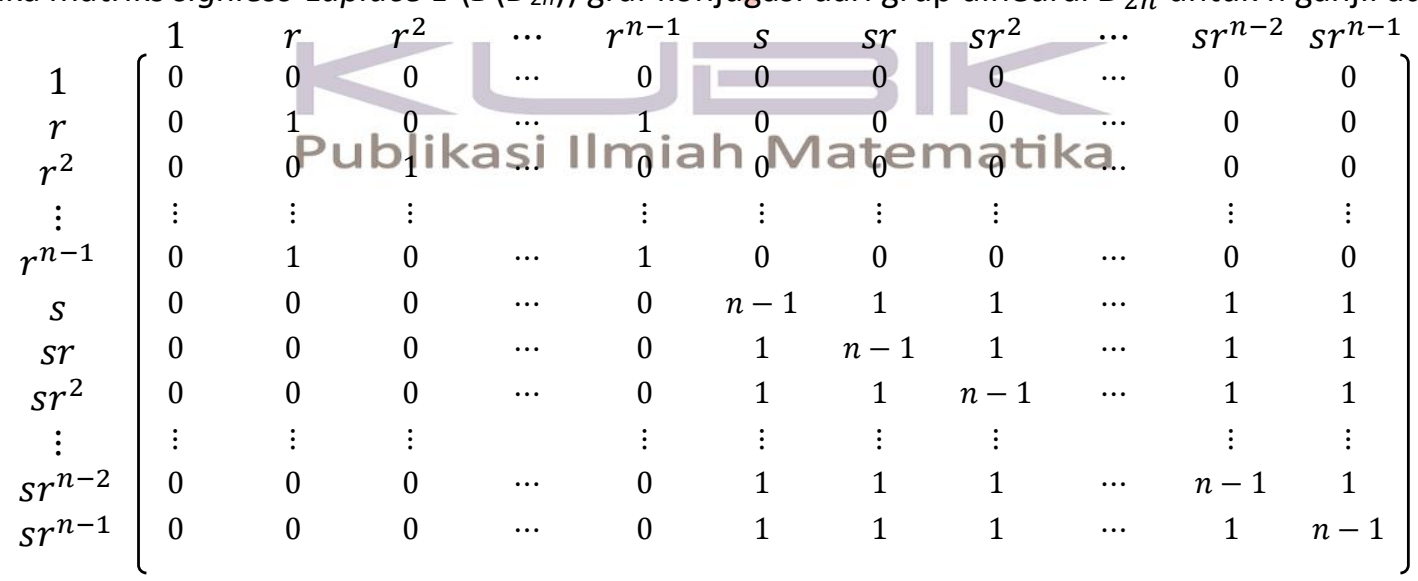

Karena polinomial karakteristik dari $L^{+}\left(\Gamma\left(D_{2 n}\right)\right)$ tidak lain adalah $\operatorname{det}\left(L^{+}\left(\Gamma\left(D_{2 n}\right)-\lambda I\right)\right)$ maka dengan mengeliminasi Gauss matriks $L^{+}\left(\Gamma\left(D_{2 n}\right)-\lambda I\right)$ menjadi matriks segitiga atas akan diperoleh $\operatorname{det}\left(L^{+}\left(\Gamma\left(D_{2 n}\right)-\lambda I\right)\right)$ sebagai perkalian semua entri pada diagonal utama matriks segitiga atas tersebut. Akhirnya diperoleh polinomial karakteristik dari $L^{+}\left(\Gamma\left(D_{2 n}\right)-\lambda I\right)$ yaitu

$$
p(\lambda)=\lambda^{\frac{n+1}{2}}(\lambda-2)^{\frac{n-1}{2}}(\lambda-(n-2))^{n-1}(\lambda-(2 n-2))
$$

\section{Teorema 2}

Spektrum signless-Laplace graf konjugasi dari grup dihedral $D_{2 n}$ untuk bilangan asli ganjil $n$ dan $n \geq 5$ adalah 


$$
\operatorname{Spec}_{L^{+}}\left(\Gamma\left(D_{2 n}\right)\right)=\left[\begin{array}{cccc}
2 n-2 & n-2 & 2 & 0 \\
1 & n-1 & \frac{n-1}{2} & \frac{n+1}{2}
\end{array}\right]
$$

Bukti

Berdasarkan Teorema 1, maka persamaan karakteristik matriks signless-Laplace graf konjugasi dari grup dihedral $D_{2 n}$ untuk bilangan asli ganjil $n$ dan $n \geq 5$ adalah

$$
p(\lambda)=\lambda^{\frac{n+1}{2}}(\lambda-2)^{\frac{n-1}{2}}(\lambda-(n-2))^{n-1}(\lambda-(2 n-2))=0
$$

Sehingga diperoleh nilai eigen yaitu $\lambda_{1}=2 n-2, \lambda_{2}=n-2, \lambda_{3}=2$, dan $\lambda_{4}=0$ dengan multiplisitas masing-masing adalah

$$
m\left(\lambda_{1}\right)=1, m\left(\lambda_{2}\right)=n-1, m\left(\lambda_{3}\right)=\frac{n-1}{2} \text {, dan } m\left(\lambda_{4}\right)=\frac{n+1}{2},
$$

Sehingga diperoleh spektrum signless-Laplace graf konjugasi dari grup $D_{2 n}$ untuk $n$ ganjil dan $n \geq 5$, yaitu

$$
\operatorname{Spec}_{L^{+}}\left(D_{2 n}\right)=\left[\begin{array}{cccc}
2 n-2 & n-2 & 2 & 0 \\
1 & n-1 & \frac{n-1}{2} & \frac{n+1}{2}
\end{array}\right] .
$$

Spektrum signless-Laplace graf konjugasi dari grup dihedral $D_{2 n}$ dengan $n$ genap belum dapat ditemukan polanya. Data yang ada menunjukkan bahwa ordo matriks spektrum signless-Laplacenya berubah-ubah. berikut.

Dari analisis pada beberapa matriks detour graf konjugasi dari grup dihedral diperolah hasil-hasil

\section{Lemma 1}

Panjang lintasan terpanjang antara dua titik pada graf konjugasi dari grup dihedral $D_{2 n}$ untuk bilangan asli ganjil $n$ dan $\mathrm{n} \geq 3$ dan $n \in N$ adalah

i. $\quad n-1$ untuk titik $s r^{i}$ dan $s r^{j}, i \neq j$ dan $1 \leq i, j<n$,

ii. 1 untuk titik $r^{i}$ dan $r^{n-i}(1 \leq i<(n-1) / 2)$,

iii. 0 untuk lainnya.

\section{Bukti}

Untuk $n$ ganjil diperoleh kelas konjugasi dari grup dihedral adalah $[1]=\{1\},[r]=\left\{r, r^{n-1}\right\},\left[r^{2}\right]=$ $\left\{r^{2}, r^{n-2}\right\}, \ldots,\left[r^{\frac{n-1}{2}}\right]=\left\{r^{\frac{n-1}{2}}, r^{\frac{n-1}{2}+1}\right\}$, dan $[s]=\left\{s, s r, s r^{2}, \ldots s r^{n-1}\right\}$. Masing-masing kelas konjugasi tersebut akan membentuk graf komplit pada graf konjugasi. Selain itu, titik-titik dalam kelas konjugasi yang berbeda tidak terhubung langsưng padá graf konjugasi. Ákibatnya,

i. Panjang lintasan terpanjang dari $s r^{i}$ ke $s r^{j}$ dengan $i \neq j$ adalah $(n-1)$.

ii. Panjang lintasan terpanjang dari $r^{i}$ ke $r^{n-i}$ adalah 1.

iii. Untuk titik selain $s r^{i}$ dan $s r^{j}$ dengan $i \neq j$, serta $r^{i}$ dan $r^{n-i}$ tidak terhubung langsung, sehingga panjang lintasan terpanjangnya adalah 0 .

Berdasarkan Lemma 1, maka matriks detour $D D\left(\Gamma\left(D_{2 n}\right)\right)$ graf konjugasi dari grup dihedral $D_{2 n}$ dengan $n$ ganjil sebagai berikut

$\left.\begin{array}{c|ccccccccccc}1 & r & r^{2} & \cdots & r^{n-1} & s & s r & s r^{2} & \cdots & s r^{n-2} & s r^{n-1} \\ 1 & 0 & 0 & 0 & \cdots & 0 & 0 & 0 & 0 & \cdots & 0 & 0 \\ r & 0 & 0 & 0 & \cdots & 1 & 0 & 0 & 0 & \cdots & 0 & 0 \\ r^{2} & 0 & 0 & 0 & \cdots & 0 & 0 & 0 & 0 & \cdots & 0 & 0 \\ \vdots & \vdots & \vdots & \vdots & & \vdots & \vdots & \vdots & \vdots & & \vdots & \vdots \\ r^{n-1} & 0 & 1 & 0 & \ldots & 0 & 0 & 0 & 0 & \ldots & 0 & 0 \\ s & 0 & 0 & 0 & \cdots & 0 & 0 & n-1 & n-1 & \cdots & n-1 & n-1 \\ s r & 0 & 0 & 0 & \cdots & 0 & n-1 & 0 & n-1 & \cdots & n-1 & n-1 \\ s r^{2} & 0 & 0 & 0 & \cdots & 0 & n-1 & n-1 & 0 & \cdots & n-1 & n-1 \\ \vdots & \vdots & \vdots & \vdots & & \vdots & \vdots & \vdots & \vdots & & \vdots & \vdots \\ s r^{n-2} & 0 & 0 & 0 & \cdots & 0 & n-1 & n-1 & n-1 & \cdots & 0 & n-1 \\ s r^{n-1} & 0 & 0 & 0 & \cdots & 0 & n-1 & n-1 & n-1 & \cdots & n-1 & 0\end{array}\right)$




\section{Teorema 3}

Polinomial karakteristik matriks detour graf konjugasi dari grup dihedral $D_{2 n}$ untuk bilangan asli ganjil $n$ dan $n \geq 3$ adalah

$$
p(\lambda)=(\lambda+(n-1))^{n-1}(\lambda+1)^{\frac{n-1}{2}}(\lambda)(\lambda-1)^{\frac{n-1}{2}}\left(\lambda-(n-1)^{2}\right)
$$

\section{Bukti}

Menggunakan eleminasi Gauss pada matriks $D D\left(\Gamma\left(D_{2 n}\right)\right)-\lambda /$ akan diperoleh matriks segitiga atas. Perkalian semua entri pada diagonal utama matriks segitigas atas tersebut adalah $\operatorname{det}\left(D D\left(\Gamma\left(D_{2 n}\right)\right)-\lambda l\right)$. Karena polinomial karakteristik dari $D D\left(\Gamma\left(D_{2 n}\right)\right)$ tidak lain adalah $\operatorname{det}\left(D D\left(\Gamma\left(D_{2 n}\right)\right)-\lambda l\right)$ maka diperoleh polinomial karakteristik

$$
p(\lambda)=(\lambda+(n-1))^{n-1}(\lambda+1)^{\frac{n-1}{2}}(\lambda)(\lambda-1)^{\frac{n-1}{2}}\left(\lambda-(n-1)^{2}\right)
$$

\section{Teorema 4}

Spektrum detour graf konjugasi dari grup dihedral $D_{2 n}$ untuk bilangan asli ganjil $n$ dan $n \geq 3$ adalah

Bukti

$$
\operatorname{Spec}_{D D}\left(\Gamma\left(D_{2 n}\right)\right)=\left[\begin{array}{ccccc}
(n-1)^{2} & 1 & 0 & -1 & -(n-1) \\
1 & \frac{n-1}{2} & 1 & \frac{n-1}{2} & n-1
\end{array}\right]
$$

Berdasarkan Teorema 3, maka persamaan karakteristik matriks detour $D D\left(\Gamma\left(D_{2 n}\right)\right)$ adalah

$$
p(\lambda)=(\lambda+(n-1))^{n-1}(\lambda+1)^{\frac{n-1}{2}}(\lambda)(\lambda-1)^{\frac{n-1}{2}}\left(\lambda-(n-1)^{2}\right)=0
$$

Maka diperoleh nilai eigen yaitu

$$
\lambda_{1}=(n-1)^{2}, \lambda_{2}=1, \lambda_{3}=0, \lambda_{4}=-1 \text {, dan } \lambda_{5}=-(n-1)
$$

dan multiplisitas masing-masing nilai eigen yaitu

Jadi

$$
m\left(\lambda_{1}\right)=1, m\left(\lambda_{2}\right)=\frac{n-1}{2}, m\left(\lambda_{3}\right)=1, m\left(\lambda_{4}\right)=\frac{n-1}{2}, \text { dan } m\left(\lambda_{5}\right)=n-1
$$

$$
\operatorname{Spec}_{D D}\left(\Gamma\left(D_{2 n}\right)\right)=\left[\begin{array}{ccccc}
(n-1)^{2} & 1 & 0 & -1 & -(n-1) \\
1 & \frac{n-1}{2} & 1 & \frac{n-1}{2} & n-1
\end{array}\right] \text {. }
$$

\section{Lemma 2}

Panjang lintasan terpanjang antara dua titik pada graf konjugasi dari grup dihedral $D_{2 n}$ dengan $n$ genap dan $n>5$ adalah
i. $\frac{n}{2}-1$ untuk titik $s r^{i}$ dan $s r^{j}, i \neq j, i$ ganjil dengan $j$ ganjil dan $i$ genap dengan $j$ genap,
ii. 1 untuk titik $r^{i}$ dap $r^{n-i}$ b́likasi Ilmiah Matematika
iii. 0 untuk lainnya.

\section{Bukti}

Misalkan $D_{2 n}=\left\{1, r, r^{2}, \ldots, r^{n-1}, s, s r, s r^{2}, \ldots, s r^{n-1}\right\}$ adalah grup dihedral dengan $\mathrm{n}$ genap dan $\mathrm{n}>$ 5. Maka kelas konjugasi yang terbentuk adalah $[1]=\{1\},\left[r^{n / 2}\right]=\left\{r^{n / 2}\right\},[r]=\left\{r, r^{n-1}\right\},\left[r^{2}\right]=\left\{r^{2}, r^{n-2}\right\}, \ldots$, $\left[r^{n / 2-1}\right]=\left\{r^{n / 2-1}, r^{n / 2+1}\right\},[s]=\left\{s, s r^{2}, s r^{4}, \ldots, s r^{n-2}\right\}$, dan $[s r]=\left\{s r, s r^{3}, s r^{5}, \ldots, s r^{n-1}\right\}$. Karena masingmasing kelas konjugasi akan membentuk graf komplit dan titik-titik dalam kelas konjugasi berbeda tidak saling terhubung langsung, maka diperoleh lintasan terpanjang antara
i. titik $s r^{i}$ dan $s r^{j}, i \neq j, i$ ganjil dengan $j$ ganjil dan $i$ genap dengan $j$ genap, adalah $\frac{n}{2}-1$.
ii. titik $r^{i}$ dan $r^{n-i}$ adalah 1 .
iii. titik-titik lainnya adalah 0 .

\section{Teorema 5}

Polinomial karakteristik matriks detour graf konjugasi dari dari grup dihedral $D_{2 n}$ untuk bilangan asli genap $n$ dan $n \geq 6$ adalah

$$
p(\lambda)=\left(\lambda+\left(\frac{n}{2}-1\right)\right)^{n-2}(\lambda+1)^{\frac{n}{2}-1}\left(\lambda^{2}\right)(\lambda-1)^{\frac{n}{2}-1}\left(\lambda-\left(\frac{n}{2}-1\right)^{2}\right)^{2} .
$$

Bukti

Berdasarkan Lemma 2, maka matriks detour $D D\left(\Gamma\left(D_{2 n}\right)\right)$ graf konjugasi dari grup dihedral $D_{2 n}$ dengan $n$ genap dan $n \geq 6$ sebagai berikut. 


\begin{tabular}{|c|c|c|c|c|c|c|c|c|c|c|c|c|c|c|c|c|}
\hline & 1 & $r$ & $r^{2}$ & $\cdots$ & $r^{\frac{n}{2}-1}$ & $r^{\frac{n}{2}}$ & $r^{\frac{n}{2}+1}$ & $\cdots$ & $r^{n-2}$ & $r^{n-1}$ & $S$ & $s r$ & $s r^{2}$ & $\cdots$ & $s r^{n-2}$ & $s r^{n-1}$ \\
\hline 1 & 0 & 0 & 0 & $\ldots$ & 0 & 0 & 0 & $\cdots$ & 0 & 0 & 0 & 0 & 0 & $\cdots$ & 0 & 0 \\
\hline$r$ & 0 & 0 & 0 & $\ldots$ & 0 & 0 & 0 & $\ldots$ & 0 & 1 & 0 & 0 & 0 & $\ldots$ & 0 & 0 \\
\hline$r^{2}$ & 0 & 0 & 0 & $\ldots$ & 0 & 0 & 0 & $\ldots$ & 1 & 0 & 0 & 0 & 0 & $\ldots$ & 0 & 0 \\
\hline$\vdots$ & $\vdots$ & $\vdots$ & $\vdots$ & & $\vdots$ & $\vdots$ & $\vdots$ & 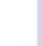 & $\vdots$ & $\vdots$ & $\vdots$ & $\vdots$ & $\vdots$ & & $\vdots$ & $\vdots$ \\
\hline$r^{\frac{n}{2}-1}$ & 0 & 0 & 0 & $\ldots$ & 0 & 0 & 1 & $\ldots$ & 0 & 0 & 0 & 0 & 0 & $\cdots$ & 0 & 0 \\
\hline$r^{\frac{n}{2}}$ & 0 & 0 & 0 & $\ldots$ & 0 & 0 & 0 & $\ldots$ & 0 & 0 & 0 & 0 & 0 & $\ldots$ & 0 & 0 \\
\hline$r^{\frac{n}{2}+1}$ & 0 & 0 & 0 & $\ldots$ & 1 & 0 & 0 & $\ldots$ & 0 & 0 & 0 & 0 & 0 & $\ldots$ & 0 & 0 \\
\hline$\vdots$ & $\vdots$ & $\vdots$ & $\vdots$ & & $\vdots$ & $\vdots$ & $\vdots$ & & $\vdots$ & $\vdots$ & $\vdots$ & $\vdots$ & $\vdots$ & & $\vdots$ & $\vdots$ \\
\hline$r^{n-2}$ & 0 & 0 & 1 & $\ldots$ & 0 & 0 & 0 & $\ldots$ & 0 & 0 & 0 & 0 & 0 & $\ldots$ & 0 & 0 \\
\hline$r^{n-1}$ & 0 & 1 & 0 & $\ldots$ & 0 & 0 & 0 & $\ldots$ & 0 & 0 & 0 & 0 & 0 & $\ldots$ & 0 & 0 \\
\hline$S$ & 0 & 0 & 0 & $\ldots$ & 0 & 0 & 0 & $\ldots$ & 0 & 0 & 0 & 0 & $\frac{n}{2}-1$ & $\ldots$ & $\frac{n}{2}-1$ & 0 \\
\hline$s r$ & 0 & 0 & 0 & $\ldots$ & 0 & 0 & 0 & $\ldots$ & 0 & 0 & 0 & 0 & 0 & $\ldots$ & 0 & $\frac{n}{2}-1$ \\
\hline$s r^{2}$ & 0 & 0 & 0 & $\ldots$ & 0 & 0 & 0 & $\ldots$ & 0 & 0 & $\frac{n}{2}-1$ & 0 & 0 & $\ldots$ & $\frac{n}{2}-1$ & 0 \\
\hline$\vdots$ & $\vdots$ & $\vdots$ & $\vdots$ & & $\vdots$ & $\vdots$ & $\vdots$ & & $\vdots$ & $\vdots$ & $\vdots$ & $\vdots$ & $\vdots$ & & $\vdots$ & $\vdots$ \\
\hline$s r^{n-}$ & 0 & 0 & 0 & $\ldots$ & 0 & 0 & 0 & $\ldots$ & 0 & 0 & $\frac{n}{2}-1$ & 0 & $\frac{n}{2}-1$ & $\ldots$ & 0 & 0 \\
\hline$s r^{n-}$ & 0 & 0 & 0 & $\ldots$ & 0 & 0 & 0 & & 0 & 0 & 0 & $\frac{n}{2}-1$ & 0 & $\ldots$ & 0 & 0 \\
\hline
\end{tabular}

Menggunakan eliminasi Gauss untuk menghitung $\operatorname{det}\left(D D\left(\Gamma\left(D_{2 n}\right)\right)-\lambda l\right)$ akan diperoleh polinomial karakteristik sebagai berikut

$$
p(\lambda)=\left(\lambda+\left(\frac{n}{2}-1\right)\right)^{n-2}(\lambda+1)^{\frac{n}{2}-1}\left(\lambda^{2}\right)(\lambda-1)^{\frac{n}{2}-1}\left(\lambda-\left(\frac{n}{2}-1\right)^{2}\right)^{2}
$$

\section{Teorema 6}

Spektrum detour graf konjugasi dari grup dihedral $D_{2 n}$ untuk bilangan asli genap $n$ dan $n \geq 6$ adalah

\section{Bukti}

$$
\operatorname{Spec}_{D D\left(D_{2 n}\right)}=\left[\begin{array}{ccccc}
\left(\frac{n}{2}-1\right)^{2} & 1 & 0 & -1 & -\left(\frac{n}{2}-1\right) \\
2 & \frac{n}{2}-1 & 2 & \frac{n}{2}-1 & n-2
\end{array}\right]
$$

Dari Teorema 5 diperoPeh/pensamaan ikarakteristikmatriks detour berikluta

$$
p(\lambda)=\left(\lambda+\left(\frac{n}{2}-1\right)\right)^{n-2}(\lambda+1)^{\frac{n}{2}-1}\left(\lambda^{2}\right)(\lambda-1)^{\frac{n}{2}-1}\left(\lambda-\left(\frac{n}{2}-1\right)^{2}\right)^{2} .
$$

Sehingga diperoleh nilai eigen

$$
\lambda_{1}=\left(\frac{n}{2}-1\right)^{2}, \lambda_{2}=1, \lambda_{3}=0, \lambda_{4}=-1, \text { dan } \lambda_{5}=-\left(\frac{n}{2}-1\right)
$$

dan multiplisitas masing-masing nilai eigen adalah

$$
m\left(\lambda_{1}\right)=n-2, m\left(\lambda_{2}\right)=\frac{n}{2}-1, m\left(\lambda_{3}\right)=2, m\left(\lambda_{4}\right)=\frac{n-1}{2} \text {, dan } m\left(\lambda_{5}\right)=2
$$

Maka spektrum detour graf konjugasi dari grup dihedral $D_{2 n}$ untuk $n$ genap dan $n \geq 6$ adalah

$$
\operatorname{Spec}_{D D}\left(\Gamma\left(D_{2 n}\right)\right)=\left[\begin{array}{ccccc}
\left(\frac{n}{2}-1\right)^{2} & 1 & 0 & -1 & -\left(\frac{n}{2}-1\right) \\
2 & \frac{n}{2}-1 & 2 & \frac{n}{2}-1 & n-2
\end{array}\right] .
$$

\section{Kesimpulan}

Hasil penelitian ini adalah rumus untuk menghitung spektrum signless-Laplace dan spektrum detour dari grup dihedral $D_{2 n}$. Penelitian selanjutnya dapat dilakukan untuk menentukan spektrum signlessLaplace graf konjugasi dari grup dihedral $D_{2 n}$ untuk $n$ genap atau menentukan spektrum signless-Laplace dan spektrum detour graf konjugasi dari grup yang lain. 


\section{Ucapan Terima Kasih}

Penulis mengucapkan terima kasih kepada Fakultas Sains dan Teknologi Universitas Islam Negeri Maulana Malik Ibrahim Malang atas bantuan dana untuk penelitian ini.

\section{Referensi}

[1] Abdussakir, N. N. Azizah, and F. F. Nofandika, Teori graf: Topik dasar untuk tugas akhir/skripsi. Malang: UIN Malang Press, 2009.

[2] G. Chartrand, L. Lesniak, and P. Zhang, Graphs and digraphs, 6th ed. Florida: CRC Press, 2016.

[3] J. A. Bondy and U. S. R. Murty, "Graph theory." Springer, New York, 2008.

[4] A. E. Brouwer and W. H. Haemers, Graph spectrum. 2012.

[5] S. K. Ayyaswamy and S. Balachandran, "On detour spectra of some graphs," Int. J. Math. Comput. Phys. Electr. Comput. Eng., vol. 4, no. 7, pp. 1038-1040, 2010.

[6] N. Biggs, Algebraic graph theory, 2nd ed. New York: Cambridge University Press, 1993.

[7] Abdussakir, R. R. Elvierayani, and M. Nafisah, "On the spectra of commuting and non commuting graph on dihedral group," Cauchy-Jurnal Mat. Murni dan Apl., vol. 4, no. May, pp. 176-182, 2017.

[8] Abdussakir, "Spektrum graf konjugasi dan komplemen graf konjugasi dari grup dihedral," Pros. Semin. Nas. Teknol. Informasi, Komun. dan Ind. 9, pp. 670-674, 2017.

[9] A. Erfanian and B. Tolue, "Conjugate graphs of finite groups," Discret. Math. Algorithms Appl., vol. 4, no. 2, pp. 1-8, 2012.

[10] S.-Y. Cui and G.-X. Tian, "The spectra and the signless Laplacian spectra of graphs with pockets," Appl. Math. Comput., vol. 315, pp. 363-371, 2017.

[11] S. R. Jog and R. Kotambari, "On the adjacency, Laplacian, and signless Laplacian spectrum of coalescence of complete graphs," J. Math., vol. 2016, pp. 1-11, 2016.

[12] S. Y. Cui and G. X. Tian, "The spectrum and the signless Laplacian spectrum of coronae," Linear Algebra Appl., vol. 437, no. 7, pp. 1692-1703, 2012.

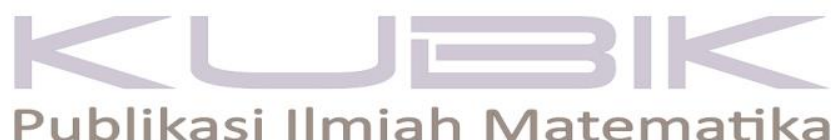

